\title{
Effective Separation for New Therapeutic Modalities Utilizing Temperature-responsive Chromatography
}

\author{
Yutaro Maekawa, Eri Ayano, Kenichi Nagase, and Hideko Kanazawa ${ }^{\dagger}$ \\ Faculty of Pharmacy, Keio University, 1-5-30 Shibakoen, Minato, Tokyo 105-8512, Japan
}

\begin{abstract}
In recent years, drug discovery and therapeutics trends have shifted from a focus on small-molecule compounds to biopharmaceuticals, genes, cell therapy, and regenerative medicine. Therefore, new approaches and technologies must be developed to respond to these changes in medical care. To achieve this, we applied a temperature-responsive separation system to purify a variety of proteins and cells. We developed a temperature-responsive chromatography technique based on a poly( $N$-isopropylacrylamide) (PNIPAAm)-grafted stationary phase. This method may be applied to various types of protein and cell separation applications by optimizing the properties of the modified polymers used in this system. Therefore, the developed temperature-responsive HPLC columns and temperature-responsive solid-phase extraction (TRSPE) columns can be an effective separation tool for new therapeutic modalities such as monoclonal antibodies, nucleic acid drugs, and cells.
\end{abstract}

Keywords Temperature-responsive chromatography, poly( $N$-isopropylacrylamide), smart functional surfaces, new therapeutic modality, monoclonal antibody, oligonucleotide, cell separation

(Received November 27, 2020; Accepted January 22, 2021; Advance Publication Released Online by J-STAGE January 29, 2021)

\section{Introduction}

In the last two decades, the development of new drugs has shifted from a focus on small-molecule compounds to large-

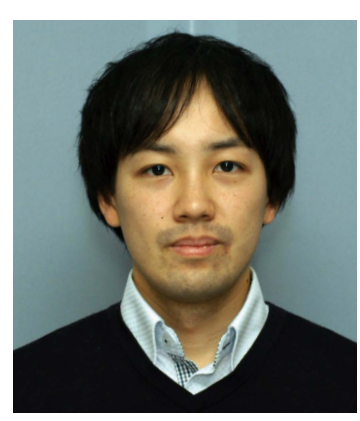

Yutaro MaEKawa received his B. Pharm. in 2014 and Ph.D. in 2021 from Keio University. His research interest has been intelligent materials for biomedical applications.
Temperature-responsive Chromatography

Utilizing a Functional Polymer Surface

P450s Substrates

Oligonucleotide Separation Using a

P(NIPAAm-co-BMA-co-DMAPAAm)

Hydrogel-modified Column
1 Introduction
659 
(a)
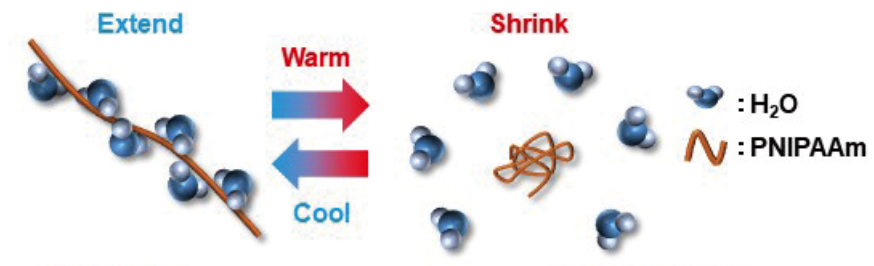

Hydrophilic

(b)
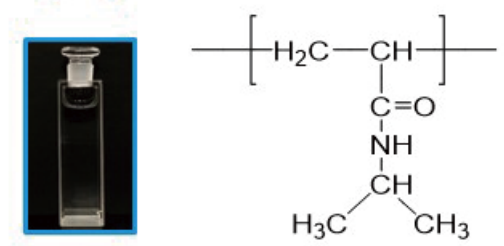

Hydrophobic

Poly(N-isopropylacrylamide)(PNIPAAm)

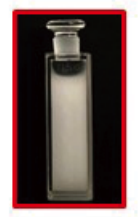

(c)

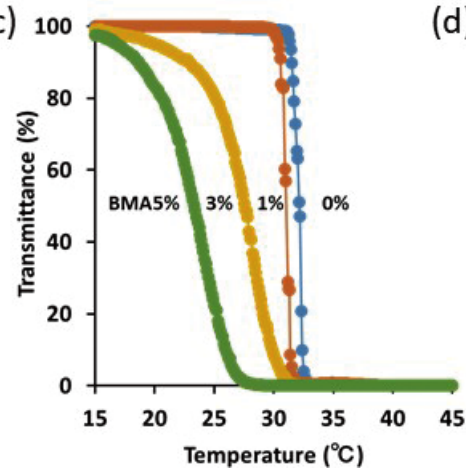

(d)

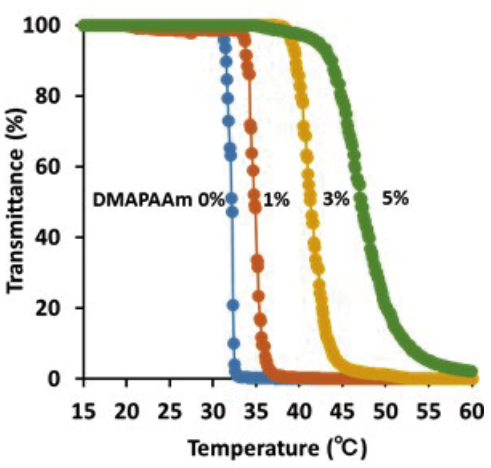

Fig. 1 Temperature-responsive polymers. (a) Illustration of temperature-dependent solubility change in the PNIPAAm chain. (b) Chemical structures of PNIPAAm and temperature-dependent solubility change in PNIPAAm in aqueous solutions. Temperature-dependent optical transmittance change of PNIPAAm copolymers aqueous solution $(0.5 \mathrm{w} / \mathrm{v} \%)$ (c) with various BMA compositions: PNIPAAm $\left(\operatorname{LCST} 32^{\circ} \mathrm{C}\right.$ ); BMA $1 \%\left(\operatorname{LCST} 30^{\circ} \mathrm{C}\right.$ ); BMA $3 \%$ (LCST $27^{\circ} \mathrm{C}$ ); BMA $5 \%$ (LCST $24^{\circ} \mathrm{C}$ ), (d) with various DMAPAAm compositions: PNIPAAm (LCST $32^{\circ} \mathrm{C}$ ); DMAPAAm $1 \%$ (LCST $35^{\circ} \mathrm{C}$ ); DMAPAAm 3\% (LCST $\left.43^{\circ} \mathrm{C}\right)$; DMAPAAm $5 \%\left(\operatorname{LCST} 49^{\circ} \mathrm{C}\right)$.

increasing. Today, seven of the ten best-selling pharmaceutics in the world are monoclonal antibodies. ${ }^{3}$ Therefore, new approaches and technologies must be developed to respond to these changes in medical care. However, to achieve the purification of biopharmaceuticals, organic, low-pH, or highsalt solvents are often employed, which sometimes results in a loss of the bioactivity of protein samples. ${ }^{4}$ Biological molecules are often separated using an ion-exchange chromatography in the medicine industry and reversed-phase chromatography and affinity chromatography, or combinations of these techniques.

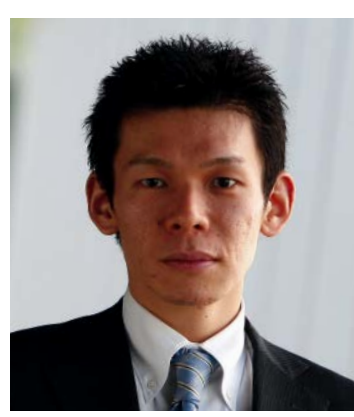

Kenichi Nagase received his Ph.D. degree in chemical engineering from Waseda University in 2005 . He is an Associate Professor of Faculty of Pharmacy, Keio University. His research interest is intelligent materials for biomedical applications, including bioseparation, tissue engineering, and regenerative medicine.
The high salt concentrations must be taken from the final product, imposing additional processing. Organic solvents have many disadvantages in terms of their cost, toxicity, flammability and disposal costs. The development of a novel separation and purification method for biopharmaceuticals, including antibodies and oligonucleotides, under mild conditions and with sustainable associated costs, is greatly required. Moreover, cells have recently been used in drug discovery, drug development, biomedical research, and biological technology and medical applications. Recently, various types of cell separation methods

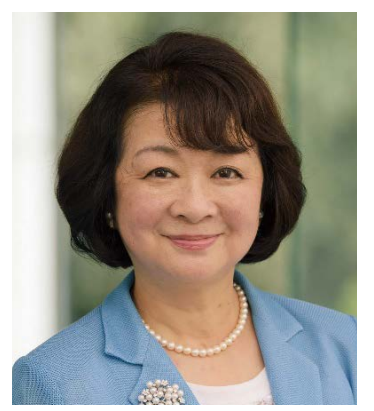

Hideko Kanazawa is Emeritus Professor of Keio University, since 2021. She received her $\mathrm{PhD}$ in Pharmaceutical Chemistry in 1991. She worked at Kyoritsu University of Pharmacy (1993 2008) and Keio University as Professor (2008 - 2020). Her research focuses on the development of functional polymerbased separation system and drug delivery system. Her research awards include the 2017 Award of The Japan Society for Analytical Chemistry, 2008 Award of The Society for Chromatographic Sciences (Japan). She was President of the Japan Society for Analytical Chemistry (2020), and Chairman of the Society for Chromatographic Sciences (20162017). 
(a)<smiles>CCC(C)N</smiles><smiles>CC1CC2CC(C1)C(C(=O)O)C2</smiles>

NHS, DCC
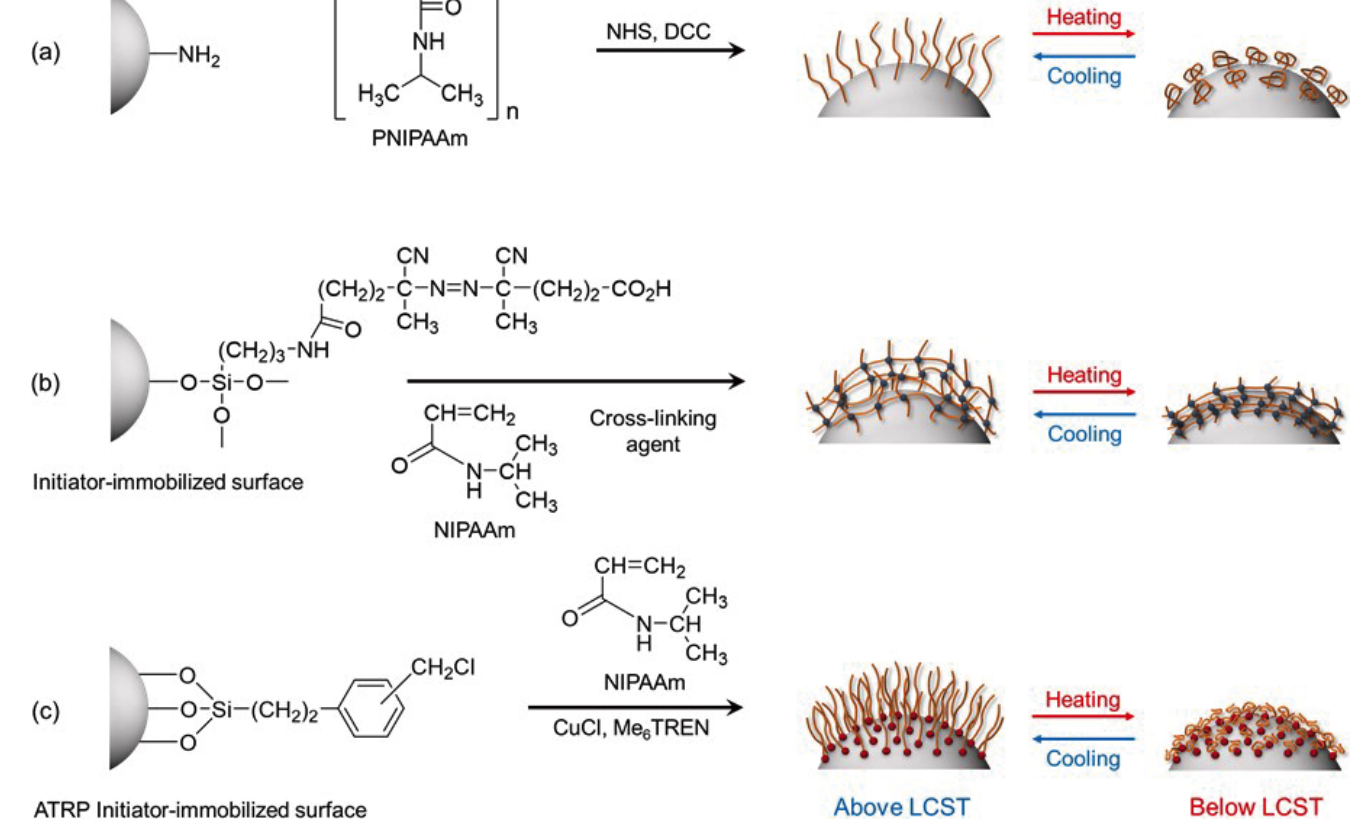

Fig. 2 Preparation of a PNIPAAm modified functionality surface on silica beads using (a) terminal modification method, (b) hydrogel modification method, and (c) ATRP method. NHS, $\mathrm{N}$-Hydroxysuccinimide; DCC, dicyclohexylcarbodiimide; $\mathrm{Me}_{6}$ TREN, Tris(2-(dimethylamino)ethyl)amine.

have been developed. ${ }^{5,6}$ Especially, a cell separation-method with maintaining cell activity is strongly required for cell transplantation.

We have been investigating a temperature-responsive chromatography system based on a poly ( $N$-isopropylacrylamide) (PNIPAAm)-grafted stationary phase. ${ }^{7-12}$ PNIPAAm is a thermosensitive polymer that exhibits a lower critical solution temperature (LCST) at $32^{\circ} \mathrm{C}$ (Fig. 1). This system is advantageous because analytes can be separated using only an aqueous mobile phase under mild conditions since the surface properties of the stationary phase are controlled by only changing the column temperature. Despite a recent increased focus on environmental protection, analytical methods that use only aqueous solutions without using organic solvents have not been well studied. Achieving separation without using organic solvents not only allows separation without impairing the function of bioactive substances, but it is also environmentally friendly. Therefore, we applied a temperature-responsive separation system to purify a variety of proteins and cells. In this paper, utilizing temperature-responsive chromatography (TRC), we reviewed a green analytical method for effective separation for new therapeutic modalities.

\section{Temperature-responsive Chromatography Utilizing a Functional Polymer Surface}

Stimuli-responsive polymers that respond to heat, ${ }^{13}$ light, ${ }^{14}$ and $\mathrm{pH}^{15,16}$ have found interesting applications in chemical and biomedical fields, such as fluorescent polymer probes ${ }^{17-24}$ and drug delivery systems. ${ }^{25-31}$ PNIPAAm is one of the most representative polymers that exhibits reversible soluble-insoluble changes in the vicinity of its LCST of around $32^{\circ} \mathrm{C}$ in aqueous solution (Fig. 1). This polymer demonstrates good solubility in aqueous solutions at low temperatures, but separates from solution when the temperature is raised above the LCST. ${ }^{32-34}$ The LCST of PNIPAAm can be controlled by the composition of the copolymer. ${ }^{35,36}$ For example, the copolymerization of NIPAAm monomers with hydrophobic monomers, such as $n$-butyl methacrylate (BMA), leads to an increase in the polymer hydrophobicity and a decrease in the LCST of the copolymer. The LCST shifts from 32 to $24^{\circ} \mathrm{C}$ as the mole fraction of BMA increases from 0 to $5 \mathrm{~mol} \%$ in the copolymer (Fig. 1c). By contrast, the copolymerization of NIPAAm monomers with more hydrophilic monomers, such as $N, N$-dimethylaminopropyl acrylamide (DMAPAAm), increases the polymer hydrophilicity while also increasing the LCST of the copolymer (Fig. 1d). These copolymers exhibit a reversible hydrophilic/hydrophobic phase transition at their LCSTs. To prepare the functional polymer surface for temperature-responsive chromatography, we used three types of modification methods for grafting the polymers onto silica beads, as shown in Fig. 2. These polymergrafted surfaces demonstrate temperature-responsive hydrophilic-hydrophobic surface property alterations. Yakushiji et al. reported temperature-dependent wettability changes for PNIPAAm hydrogel modified surfaces by aqueous dynamic contact-angle measurements. ${ }^{37}$ The graft configuration of PNIPAAm produced from different grafting methods greatly influences temperature-dependent aqueous wettability changes. Using these features, we developed temperature-sensitive stationary phases for HPLC ${ }^{38-42}$ and solid-phase extraction (SPE) ${ }^{43}$ Unlike in conventional HPLC systems, such as reversephase columns in which the partitioning is controlled by the mobile phase composition, the partitioning in temperatureresponsive chromatography systems is controlled by external temperature changes, and the aqueous solution is used as the mobile phase.

We designed and synthesized multi-functional polymers based 
Table 1 Multi-functional polymers based on PNIPAAm for separation of various samples

\begin{tabular}{|c|c|c|c|c|}
\hline \multirow{2}{*}{ Polymer } & \multirow{2}{*}{ Separation mode } & \multicolumn{2}{|r|}{ Application } & \multirow{2}{*}{ Reference } \\
\hline & & Type & Detail & \\
\hline \multirow[t]{2}{*}{ PNIPAAm } & \multirow[t]{2}{*}{ Hydrophobic interactions } & Peptide/Protein & Insulin, lysozyme & 64 \\
\hline & & Small molecule & $\begin{array}{l}\text { Steroid, PTH-amino acid, naphthalene, } \\
\text { 1,5-dinitronaphthalene }\end{array}$ & $38,40,68,69,70$ \\
\hline $\begin{array}{l}\text { P(NIPAAm-co-AAc- } \\
c o \text {-tBAAm) }\end{array}$ & $\begin{array}{l}\text { Hydrophobic interactions } \\
\text { Electrostatic interactions }\end{array}$ & Cell & $\begin{array}{l}\text { Human dermal fibroblasts (NHDF), aortic } \\
\text { smooth muscle cells (SMC), umbilical vein } \\
\text { endothelial cells (HUVEC) }\end{array}$ & 72 \\
\hline $\begin{array}{l}\text { P(NIPAAm-co-AAc- } \\
\text { co-BMA) }\end{array}$ & $\begin{array}{l}\text { Hydrophobic interactions } \\
\text { Electrostatic interactions }\end{array}$ & $\begin{array}{l}\text { Antibody, Peptide/ } \\
\text { Protein }\end{array}$ & Rituximab, lysozyme, ovalbumin, albumin & 43 (SPE) \\
\hline $\mathrm{P}(\mathrm{NIPAAm}-\mathrm{co}-\mathrm{BMA})$ & Hydrophobic interactions & Small molecule & $\begin{array}{l}\text { Propofol, steroid, CYP substrate and metabolite } \\
\text { Theophylline, phenytoin } \\
\text { Barbiturates and benzodiazepine }\end{array}$ & $\begin{array}{l}39,48,51,71,72 \\
59(\mathrm{SPE}) \\
74(2 \mathrm{D}-\mathrm{HPLC})\end{array}$ \\
\hline $\begin{array}{l}\text { P(NIPAAm- } c o-B M A- \\
\text { co-DMAEMA) }\end{array}$ & $\begin{array}{l}\text { Hydrophobic interactions } \\
\text { Electrostatic interactions }\end{array}$ & Peptide/Protein & Albumin & 64 \\
\hline \multirow{5}{*}{$\begin{array}{l}\text { P(NIPAAm-co-BMA- } \\
\text { co-DMAPAAm) }\end{array}$} & Hydrophobic interactions & Cell & HL-60 and Jurkat cell & 66 \\
\hline & Electrostatic interactions & Oligonucleotide & $\begin{array}{l}\text { Oligonucleotide, phosphorothioated } \\
\text { oligonucleotide, adenosine nucleotides (AMP, } \\
\text { ADP, ATP) }\end{array}$ & $61,75,76$ \\
\hline & & Peptide/Protein & Albumin & 43 (SPE) \\
\hline & & Small molecule & Steroid, NSAIDs, phospho-tyrosine & 75,77 \\
\hline & & & Theophylline, phenytoin & 43 (SPE) \\
\hline $\begin{array}{l}\text { P(NIPAAm- } c o-\mathrm{L}-\mathrm{Phe}- \\
\mathrm{OMe})\end{array}$ & $\begin{array}{l}\text { Hydrophobic interactions } \\
\text { Molecular recognition }\end{array}$ & Small molecule & Steroid, PTH-amino acid & 49 \\
\hline \multirow{2}{*}{$\begin{array}{l}\text { P(NIPAAm- } c o-\text {-L-Pro- } \\
\text { OMe })\end{array}$} & Hydrophobic interactions & Peptide/Protein & Angiotensin, bradykinin & 48 \\
\hline & Molecular recognition & Small molecule & Steroid, PTH-amino acid & 46,48 \\
\hline $\begin{array}{l}\text { P(NIPAAm- } c o-\mathrm{L}-\text { Trp- } \\
\text { OMe })\end{array}$ & $\begin{array}{l}\text { Hydrophobic interactions } \\
\text { Molecular recognition }\end{array}$ & Small molecule & $\begin{array}{l}\text { Steroid, PTH-amino acid, CYP substrate, } \\
\text { psychoactive drugs }\end{array}$ & $49,50,51$ \\
\hline $\begin{array}{l}\text { P(NIPAAm-co-Nap- } \\
\text { OMe) }\end{array}$ & $\begin{array}{l}\text { Hydrophobic interactions } \\
\text { Molecular recognition }\end{array}$ & Small molecule & Steroid, naphthalene, 1,5-dinitronaphthalene & 47,48 \\
\hline PNIPAAm, PAMPS & $\begin{array}{l}\text { Hydrophobic interactions } \\
\text { Electrostatic interactions }\end{array}$ & Small molecule & Cold medicine, monoamines, DOPA, tyramine & 78 (mixed-mode) \\
\hline
\end{tabular}

on PNIPAAm to optimize the separation of various samples (Table 1). By introducing cationic or anionic comonomers in polymer chains as a function of the ion-exchange group, these copolymers respond to both the temperature and $\mathrm{pH}$. For example, cationic DMAPAAm (pKa: 10.4) may be protonated in an aqueous solution at $\mathrm{pH} 7.4$ while providing hydrophilicity to the copolymer..$^{35,36}$ The phase-transition temperature of the polymer increases with increasing DMAPAAm composition (Fig. 1d). Hoffman et al. ${ }^{44}$ reported that the LCST of a NIPAAm and acrylic acid (AAc) copolymer increased with an increase in the $\mathrm{pH}$ of the used buffer solutions. Kobayashi et al. ${ }^{45}$ reported that terpolymer poly(NIPAAm- $\mathrm{co}$-AAc-co-tBAAm) showed apparent carboxylate $\mathrm{pKa}$ shifts, depending on the temperature in water.

As shown in Table 1, we synthesized a thermo-responsive polymer containing aromatic amino acid moieties as molecularrecognition sites for development as stationary phases for HPLC. ${ }^{46-51}$ The grafted stationary phases consisted of functional copolymers composed of NIPAAm and $\mathrm{N}$-acryloyl aromatic amino acid methyl esters, including phenylalanine and tryptophan methyl esters (Phe-OMe and Trp-OMe). Two novel temperature-responsive polymers, namely poly(NIPAAm-coPhe-OMe) and poly(NIPAAm-co-Trp-OMe), were synthesized and grafted onto aminopropyl silica. These temperatureresponsive polymer-modified beads were then packed into the stainless-steel column and used in the HPLC-system (TRHPLC). Figure 3 shows the effects of amino acid introduction to polymer chains on steroid separation. In the separation of steroids with varied hydrophobicities, more hydrophobic steroids are retained longer. This indicates that $\pi-\pi$ interactions occurred between the steroids and the phenyl or indole moieties of phenylalanine or tryptophan, respectively. In addition, the retention of compounds with hydrogen bond acceptors were higher in a poly(NIPAAm-co-Trp-OMe5\%)-modified column, which contained indole as a hydrogen bond donor, than in a poly(NIPAAm-co-Phe-OMe5\%)-modified one. ${ }^{48,49}$ Satti et al. reported that the incorporation of selected moieties next to the temperature-responsive polymers has a strong influence on the retention behavior. ${ }^{52}$

TRC that utilizes smart, functional surfaces utilizes weak and reversible non-covalent interactions between molecules, including hydrogen bonds, ionic interactions, $\pi-\pi$ interactions, and/or hydrophobic interactions. These types of non-covalent binding interactions contribute to protein secondary structures and diverse drug-receptor interactions. Non-covalent binding interactions (i.e., $\pi-\pi$ interactions and hydrogen bonding, as well as hydrophobic and electrostatic interactions) may be modulated by temperature changes. Therefore, the TRC method will be effective for the separation of biopharmaceuticals and complex molecular recognition processes.

PNIPAAm-based stationary phase have also been reported for size exclusion chromatography (SEC) and reversed-phase liquid chromatography (RPLC). In SEC, porous glass beads ${ }^{53}$ or porous polymer beads ${ }^{54}$ modified with PNIPAAm allowed for control of the pore size by temperature. Moreover, Go et al. ${ }^{55}$ reported on the effects of the mobile-phase composition and temperature on the selectivity of PNIPAAm-bonded silica gel in RPLC. 


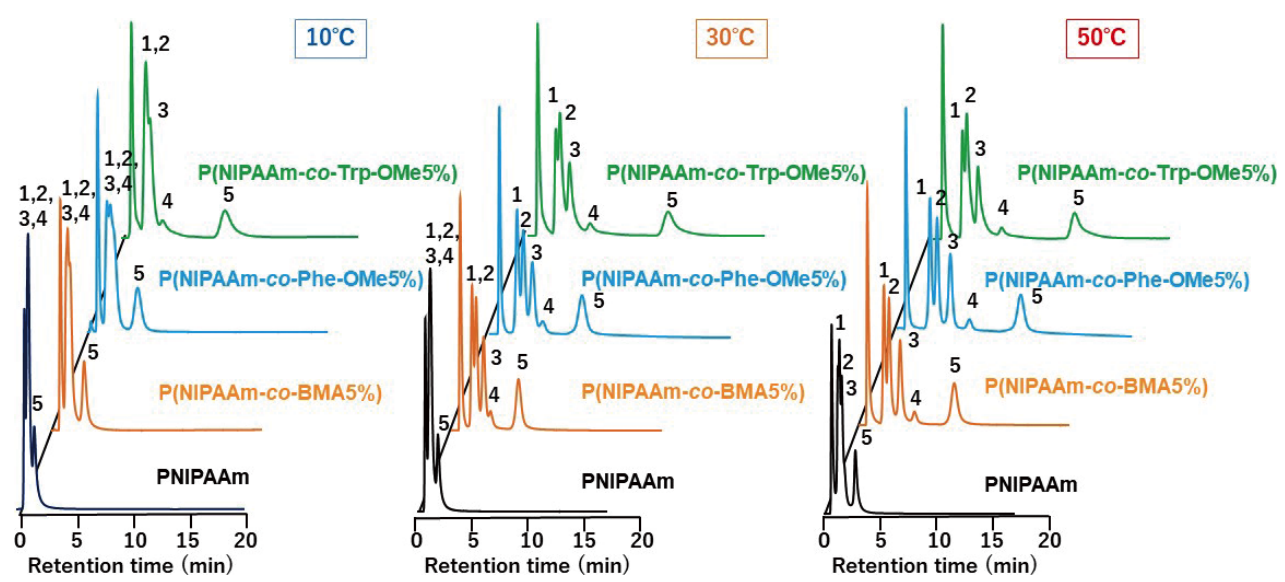

Fig. 3 Chromatograms of a mixture of steroids on PNIPAAm, P(NIPAAm-co-BMA5\%), poly(NIPAAm-co-Phe-OMe $5 \%$ ), and poly(NIPAAm- $c o$-Trp-OMe $5 \%$ ) modified column at 10, 30 and, $50^{\circ} \mathrm{C}$. Peak numbers: 1 , hydrocortisone $(\log P=1.61) ; 2$, prednisolone $(\log P=1.62) ; 3$, dexamethasone ( $\log P=1.83) ; 4$, hydrocortisone acetate $(\log P=2.30) ; 5$, testosterone $(\log P=3.32)$.

\section{Simultaneous Analysis of Multiple Cytochrome P450s Substrates}

Cytochrome p450s (CYP) comprise a superfamily of hemethiolate proteins, and are best known for their central role in phase-I drug metabolism. ${ }^{56,57}$ They are of critical importance for overcoming significant clinical pharmacological problems, including drug interactions and interindividual variability in drug metabolism. ${ }^{58,59}$ The "cocktail" approach is often used in drug development to estimate the effect of more than one single experimental CYP enzyme of a drug candidate. A simultaneous analysis of more than one CYP substrate, which may have the very different structures and physicochemical properties, generally requires organic solvents and a mobile-phase gradient method in a conventional system. ${ }^{60,61}$ In contrast, when PNIPAAm-based temperature-responsive chromatography is used, a simultaneous analysis of cocktails of multiple CYP substrates and their metabolites may be achieved with isocratic and single mobile phases. In TR-HPLC, a good separation of six CYP substrates, such as phenacetin for CYP1A2, coumarin for CYP2A6, tolbutamide for CYP2C9, S-mephenytoin for CYP2C19, chlorzoxazone for CYP2E1, and testosterone for CYP3A4 were achieved utilizing a P(NIPAAm-co-BMA)modified silica column, as shown in Fig. 4. As shown in Fig. 5b, good separation of the CYP3A4 substrate, midazolam, and its metabolite, 1'-hydroxymidazolam, was achieved using only an aqueous mobile phase without the requirement of any complicated gradient methods for the mobile phase. Interestingly, the order of elution of midazolam and its metabolite was changed at higher column temperatures, as shown in Fig.5a. Figure 5c shows plots of the retention factor against the column temperature, obtained from Fig. 5a. It could be interpreted that the surface property alteration of the stationary phase at higher temperatures than the LCST caused changing interactions between the polymer surface and the analytes.

Recently, Maekawa et al. reported that five CYP substrates, such as caffeine for CYP1A2, warfarin for CYP2C9, omeprazole for CYP2C19, dextromethorphan for CYP2D6, and midazolam for CYP3A4, were analyzed utilizing a P(NIPAAm-co-Trp$\mathrm{OMe}$ )-modified silica column. ${ }^{51}$ Introducing comonomers into the polymer unit can significantly enhance molecular recognition
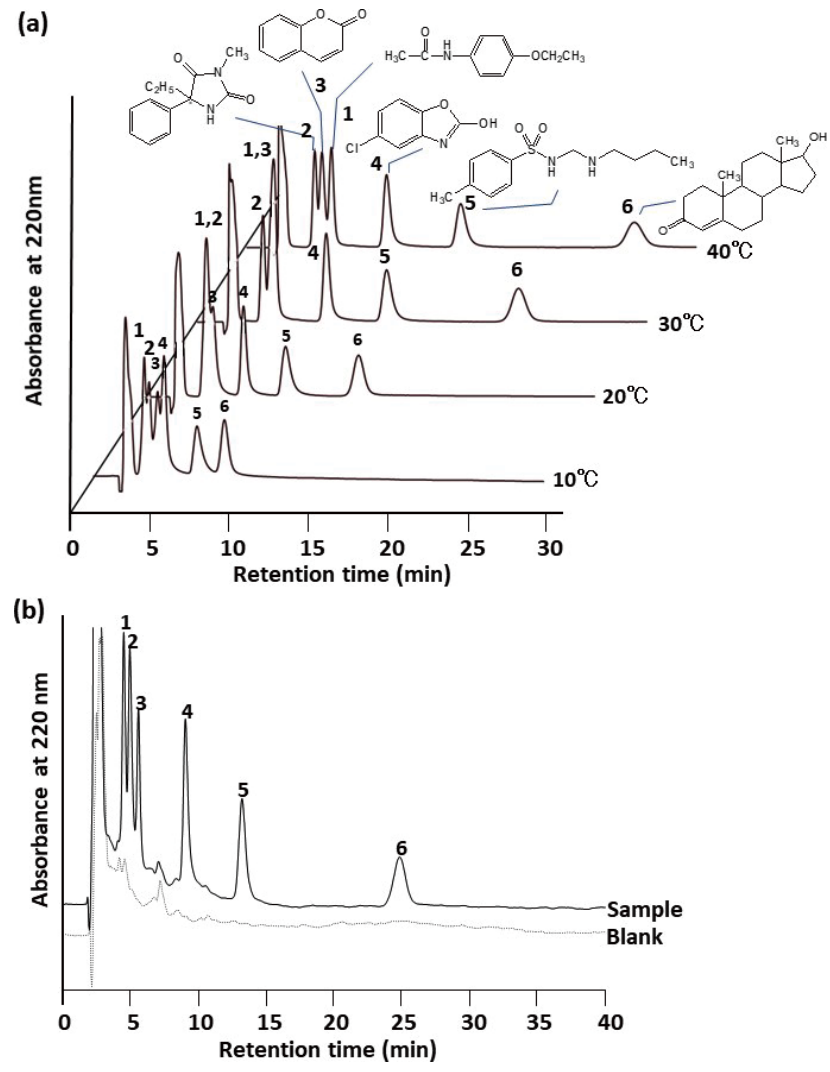

Fig. 4 Simultaneous analysis of cytochrome p450s substrates. (a) Chromatograms of a mixture of CYP probe substrates. HPLC conditions, flow-rate: $1.0 \mathrm{~mL} / \mathrm{min}$, column: $\mathrm{P}(\mathrm{NIPAAm}-\mathrm{co}$-BMA5\%) terminally-modified column $(4.6 \varphi \times 150 \mathrm{~mm})$, eluent: $\mathrm{CH}_{3} \mathrm{COONH}_{4}$ (pH 4.8), detection: UV $220 \mathrm{~nm}$. Peak No. 1: phenacetin, 2: S-mephenytoin, 3: coumarin, 4: chlorzoxazone, 5: tolbutamide, 6: testosterone. (b) Chromatogram of six CYP substrates spiked in urine.

by the column.

This method is quite useful for various purposes because molecular recognition can be expanded and/or enhanced by introducing different comonomers into the polymer unit. PNIPAAm-based temperature-responsive chromatography 


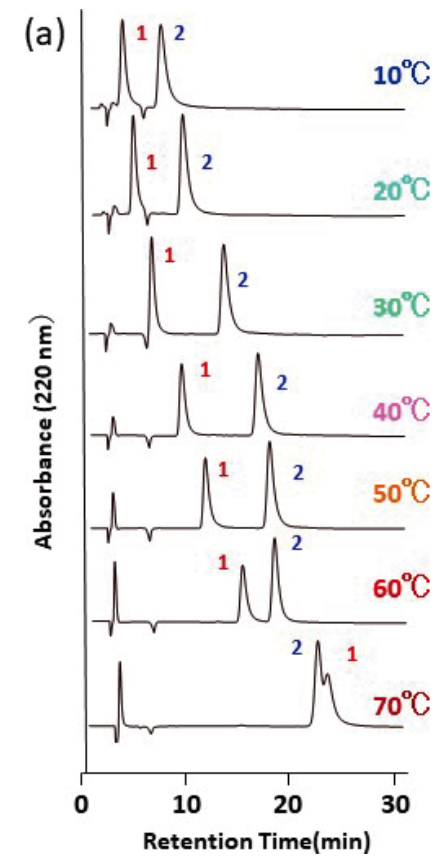

(b)

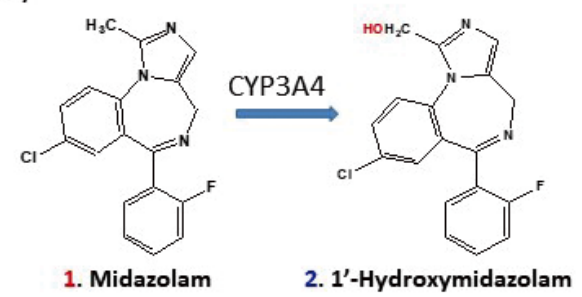

(c)

Fig. 5 (a) Chromatograms of midazolam (CYP3A4 substrate) and its metabolite on P(NIPAAm-coBMA5\%) modified column at various temperatures. Samples: 1, midazolam; 2, 1'-hydroxymidazolam; HPLC conditions is the same as Fig. 4. (b) Structure of midazolam and its metabolite. (c) Effect of temperature on the retention factors.

requires less time to optimize the mobile phase and requires less skill compared to conventional reversed-phase liquid chromatography (RPLC) because the physical properties of the stationary phase can be easily controlled by only changing the temperature. Moreover, this chromatographic method does not require any toxic organic solvents. This is advantageous not only because it maintains biological activity, but also because of the benefits to consumer and environmental health. PNIPAAmbased temperature-responsive chromatography may be used as a simultaneous bioanalytical method for multiple CYP substrates used during drug development and may replace conventional analysis methods.

\section{Oligonucleotide Separation Using a P(NIPAAm- co-BMA-co-DMAPAAm) Hydrogel-modified Column}

For over 30 years, oligonucleotide drugs have been developed to treat such diseases as diabetes, cancer, and HIV/AIDS. Recently, considerable progress has been made in overcoming challenges related to their administration, biodistribution, cellular uptake, and undesired side effects, and several drugs have received regulatory approval. During oligonucleotide synthesis, the drug substance is synthesized onto a solid support. A number of different purification steps are required, especially chromatographic purification and analysis that enable the recognition of slight structural differences following synthesis.

TRC using P(NIPAAm-co-BMA-co-DMAPAAm) hydrogelmodified silica beads helped recognize differences in the lengths of single nucleotides, terminal single bases, and the number of sites (Fig. 6a). The elution behaviors of three oligonucleotides with different lengths (dpT10, dpT15, and dpT20) were observed with the P(NIPAAm-co-BMA-co-DMAPAAm) hydrogel modified TRC column $(2.1$ i.d. $\times 50.0 \mathrm{~mm})$ at various column temperatures using a phosphate buffer ( $\mathrm{pH}$ 7.0) as the mobile phase. Combinations of multiple oligonucleotides were well separated by this TRC, as shown in Figs. $6 \mathrm{~b}$ and $6 \mathrm{c}$. The retention of oligonucleotides was increased by increasing the temperature, opposite to the behavior exhibited by conventional RPLCs. The separation of single nucleobases in oligonucleotides, such as guanine $(\mathrm{G})$, cytosine $(\mathrm{C})$, thymine $(\mathrm{T})$, or adenine $(\mathrm{A})$, was also achieved using the P(NIPAAm-co-BMA-coDMAPAAm) hydrogel-modified column. ${ }^{62}$

Nucleic acids are highly susceptible to degradation by endogenous nucleases, and phosphorothioate oligonucleotides (commonly referred to as S-oligos) are often used in these systems because of their resistance to cellular nuclease degradation. In conventional RPLC, the separation of S-oligos require an organic solvent with an ion-pairing reagent, such as tetraethylamine-acetic acid, as the mobile phase and gradient elution. In contrast, Maekawa et al. recently reported that good separation of multiple phosphorothioated oligonucleotides was obtained by TR-HPLC using a P(NIPAAm-co-BMA-coDMAPAAm) hydrogel-modified column with an aqueous solvent and an isocratic elution without ion-pairing reagents. ${ }^{62}$

These results indicate that TR-HPLC is well-suited for ensuring the quality and safety of therapeutic oligonucleotides.

\section{Temperature-responsive Solid-phase Extraction Column for Protein Purification}

The biopharmaceutical market has been rapidly growing, and eight of the ten top-selling drugs in the world are currently biopharmaceuticals. In particular, antibody drugs are in high demand due to their typically small number of side effects. The market for therapeutic monoclonal antibodies (mAbs) has also grown tremendously over the last decade.

However, one issue associated with antibody-drugs is their 

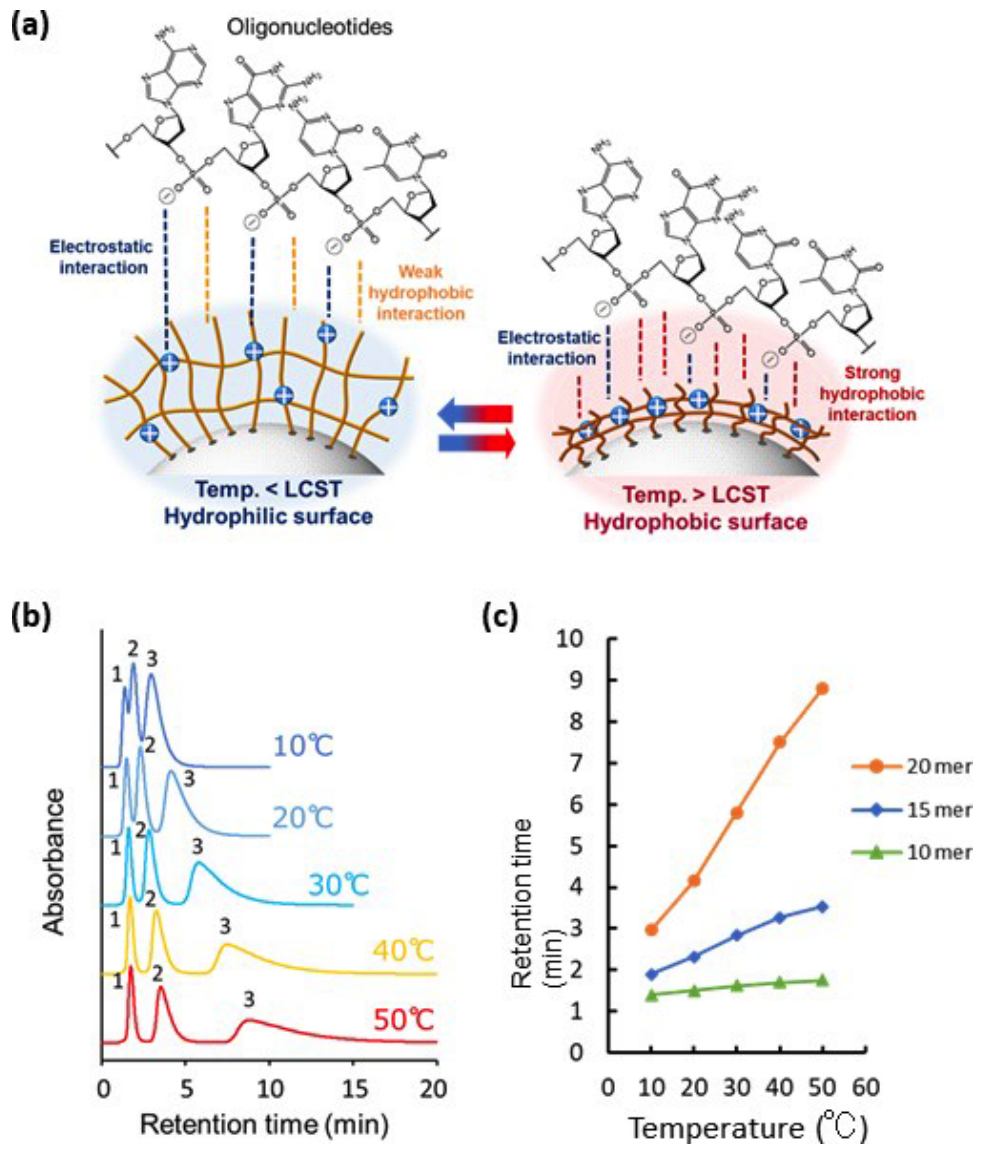

Fig. 6 Separation of oligonucleotides using a P(NIPAAm-co-BMA-co-DMAPAAm) hydrogelmodified column. (a) Electrostatic and hydrophobic interaction between ionic copolymer-modified surface and oligonucleotides. (b) Chromatograms of oligonucleotides. (c) Effect of temperature on the retention times of oligonucleotides.

high price, and the high price of antibody-drugs increases the burden on patients. Because $66 \%$ of the manufacturing costs of antibodies results from the purification process, ${ }^{63}$ a highly efficient purification method is needed. Several antibodies may aggregate under low $\mathrm{pH}$ conditions during the purification process. This aggregation results in the loss of their bioactivities and a decreased the purification efficiency. Therefore, developing a novel purification method for proteins, such as antibodies, under mild conditions and with sustainable costs is greatly required.

Utilizing TRC in HPLC system, we have reported successful protein separation without the loss of bioactivity with an aqueous mobile phase without using an organic solvent. ${ }^{64}$ Furthermore, we developed a temperature-responsive solidphase extraction (TR-SPE) column to purify a variety of proteins. ${ }^{43}$ The surfaces of aminopropyl silica beads (with an average diameter of 40 to $64 \mu \mathrm{m}$ ) were modified with hydrogels of a PNIPAAm copolymer, and then packed into a PTFE column for SPE. A retention of proteins results from the hydrophobicity of the NIPAAm and BMA moieties, as well as the electrostatic interactions of AAc in the temperature-responsive polymer. SPE is easy to use, can be automated, and is less expensive compared to other extraction methods. It is also possible to scale-up this process for applications in the industrial purification of biopharmaceuticals.

Rituximab is a chimeric monoclonal antibody towards the antigen CD20, and it has been widely evaluated in B cell hematological malignancies. Rituximab may be purified from a hybridoma cell culture medium using the developed P(NIPAAmco-BMA-co-AAc) hydrogel-modified TR-SPE column (Fig. 7). The denaturation of rituximab was not observed in the fraction eluted from the TR-SPE column (Fig. 7b). During purification, rituximab did not elute at the washing step, while most of the contaminants were eluted, as shown in Figs. 7b and 7c. The reactivity of the antibody to $\mathrm{CD} 20$ positive cells after purification was equivalent that of the sample before purification; thus, the maintenance of antibody activity after purification was confirmed (Fig. 7d). Figure 7e, shows that a good separation of rituximab was obtained from a mixture of MAbs with the same constant region. This indicates that recognizing differences in the variable region of MAb can be achieved by altering the temperature. These results demonstrate that the developed TRSPE column can be applied in biomedical purification processes, which maintaining the biological activity of the proteins. ${ }^{65}$

\section{Temperature-modulated Cell Separation Using P(NIPAAm-co-BMA-co-DMAPAAm) Hydrogel- modified Packing Materials}

In recent years, cell transplantation therapy to recover the functions of tissues and organs has attracted attention. Kymriah was recently approved by the Japanese Ministry of Health, Labour, and Welfare in 2019, becoming the first chimeric antigen receptor T-cell (CAR-T) therapy to be approved in Japan. CAR-T therapy is one of the most promising approaches 
(a)

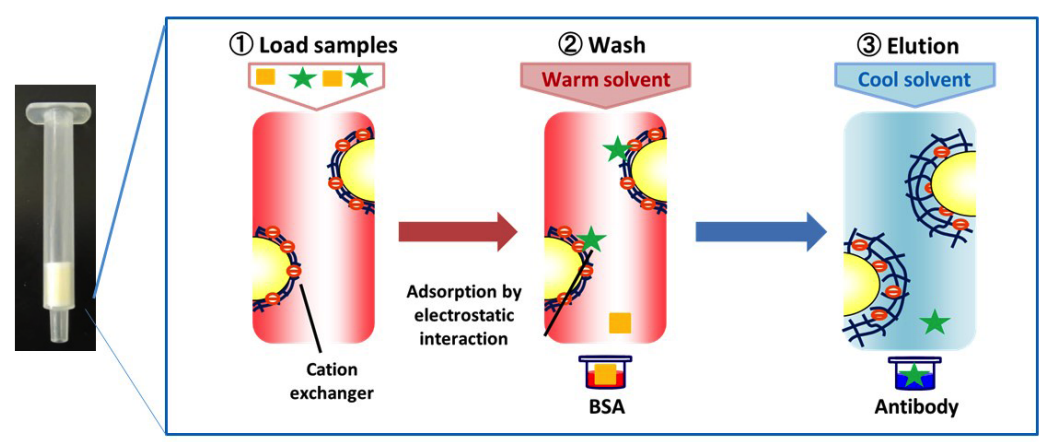

(b)

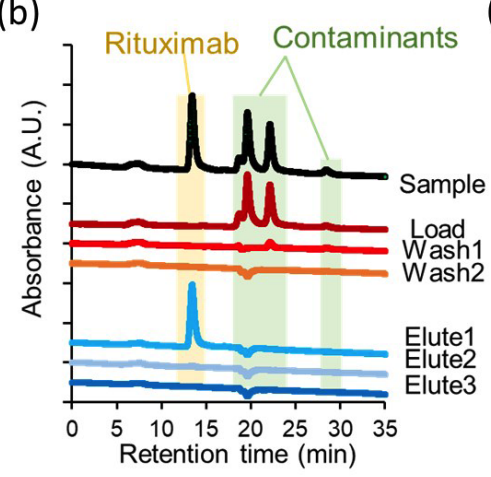

(d)

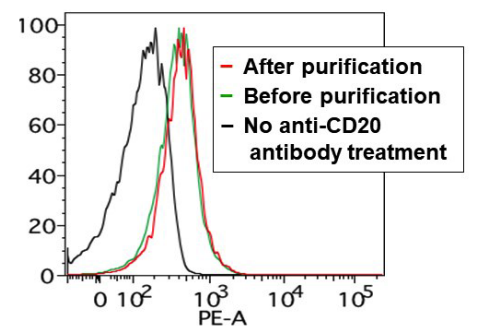

(c)

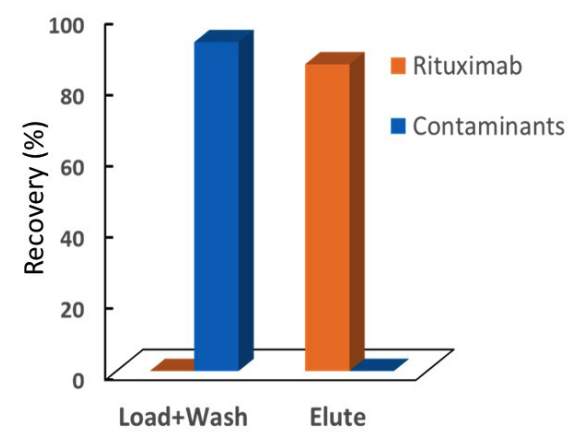

(e)

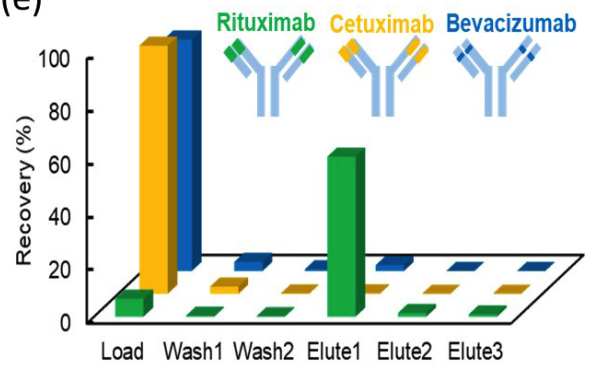

Fig. 7 Temperature-responsive P(NIPAAm-co-BMA-co-AAc) hydrogel-modified solid-phase extraction column for antibody purification. (a) Concept of purification of rituximab from the hybridoma cell culture media using TR-SPE column. (b) GPC chromatograms of each fraction. (c) Elution profile and recovery rate of each fraction. (d) Reactivity of antibody to CD20 positive cells. (e) Elution profile and recovery rate of the mixture of MAbs with the same constant region.

in anticancer therapy, and it has been hailed as a revolutionary, final method for people with advanced cancer following previous treatment. However, CAR-T therapies involve some of the most expensive drugs in the pharmaceutical market.

By utilizing P(NIPAAm-co-BMA-co-DMAPAAm) hydrogel modified TR-SPE system, in which silica beads with average diameters of 100 to $150 \mu \mathrm{m}$ were used for optimizing the column towards the size of blood cells, temperature-dependent cell elution behavior was observed in the separation of HL-60 and Jurkat cells (leukemia cells) (Fig. 8). Both cell types were retained in columns containing beads with cationic properties at $37^{\circ} \mathrm{C}$, whereas beads without cationic properties did not retain the cells. At $37^{\circ} \mathrm{C}$, cells can be retained in the column through both electrostatic and hydrophobic interactions, and the cells are eluted at $4^{\circ} \mathrm{C}$ because of reduced hydrophobic interactions. The cell retention and elution behaviors were changed by varying the content of the cationic group in the copolymer. The cell retention mainly resulted from electrostatic interactions between the polymer on the beads and the cell surfaces. These results indicate that the retention and elution of cells by the prepared beads packed into the TR-SPE column can be simply modulated by changing the temperature of the system. ${ }^{66}$ The effects of modulating the temperature of the column separation process on the cell activity, cell morphology, and viability at each column separation step was observed. The cell morphologies of the HL60 and Jurkat cells did not change before and after passing through the column. In addition, the passage culture of the eluted cells can be achieved without demonstrating any morphological changes. The cell viability determined via the trypan blue assay remained constant both before and after passing through the column, as well as after obtaining a passage culture of the eluted cells. These results indicate that the column separation does not affect the cell viability. The prepared column can be applied to various types of cell separation by optimizing the properties of the modified polymer on the beads. This was the first report of successful cell separation using a temperature-responsive column. ${ }^{66}$

Recently, Nagase et al. reported on the use of thermoresponsive cationic block copolymer brushes for temperature-modulated stem cell separation. ${ }^{67}$ They prepared a thermoresponsive cationic block copolymer brush made on a glass surface using a two-step activator regenerated by an electron transfer (ARGET)- 
(a)
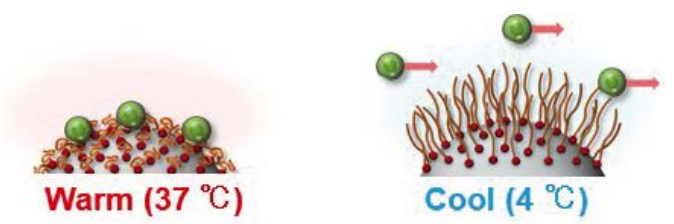

(b)

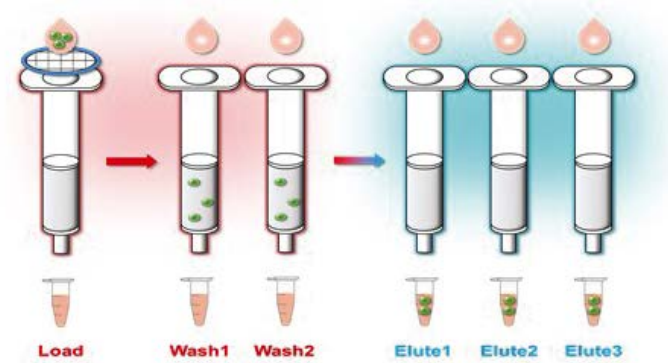

(c)

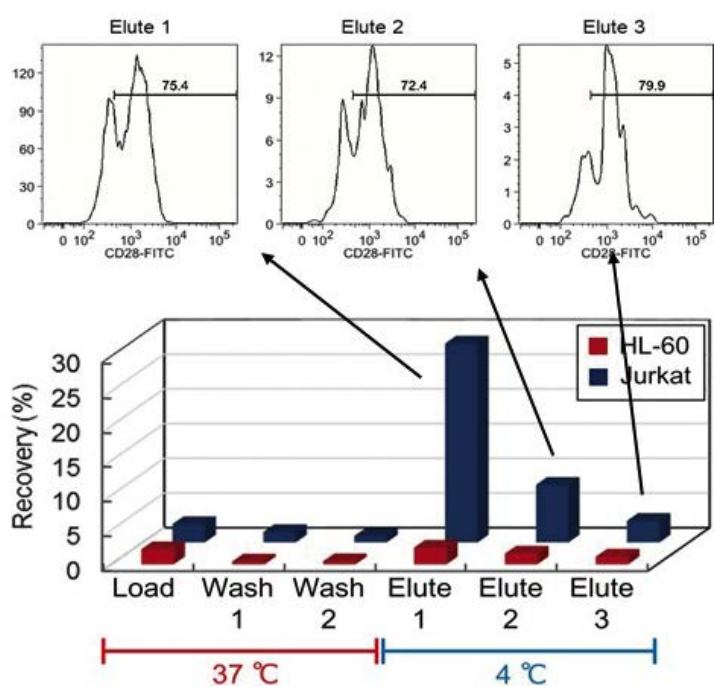

Fig. 8 Temperature-modulated cell separation using P(NIPAAm-coBMA-co-DMAPAAm) hydrogel-modified TR-SPE column. (a) Concept of interaction between polymer-modified surface and cells. (b) Protocol of cell separation using TR-SPE column. (c) Flow cytometry analysis of each fraction. (d) Elution profiles of HL-60 and Jurkat cells.

atom transfer radical polymerization (ATRP) process. Using this copolymer brush, umbilical-cord-derived mesenchymal stem cells (UCMSC) could be purified from a cell mixture (consisting of fibroblasts and macrophages) by simply changing the temperature.

We believe that the cell-separation method developed in this study and similar methods developed in previous studies utilizing simple, versatile, and inexpensive materials are of important value for biological research. Furthermore, these methods provide an alternative for increasing the purification efficiency of protocols for biopharmaceutical drugs while reducing production costs.

\section{Conclusions}

Using TR-HPLC with an aqueous mobile phase, the simultaneous analysis of multiple CYP substrates and the successful separation of oligonucleotides were achieved. Monoclonal antibodies were successfully separated from typical contaminants without the occurrence of hydrolysis and aggregation. The results indicate that the developed temperature-responsive SPE column can be applied in the purification of biomedical substances with low costs and may act as an effective cell separation tool for biomedical applications. The proposed separation system may also be applicable to various types of protein and cell separations, as well as purification in drug discovery by optimizing the properties of modified polymers. Therefore, the developed temperature-responsive column can be an effective protein and cell separation tool for applications in bioindustries.

\section{Acknowledgements}

This work was partially financially supported by a SENTAN grant (JPMJSN16B3) from JST, a Grant-in-Aid for Scientific Research (grant nos. 16H05083 and 19H02447) from JSPS, and AMED under Grant Number JP20mk0101171.

\section{References}

1. E. Valeur, S. M. Guéret, H. Adihou, R. Gopalakrishnan, M. Lemurell, H. Waldmann, T. N. Grossmann, and A. T. Plowright, Angew. Chem. Int. Ed. Engl., 2017, 56, 10294.

2. L. Gutierrez, N. S. Cauchon, T. R. Christian, M. J. Giffin, and M. J. Abernathy, J. Pharm. Sci., 2020, 109, 3524

3. L. Urquhart, Nat. Rev. Drug Discov., 2020, 19, 228.

4. P. Maharjan, B. W. Woonton, L. E. Bennett, G. W. Smithers, K. DeSilva, and M. T. W. Hearn, Innov. Food Sci. Emerg. Technol., 2008, 9, 232.

5. N. Ota, Y. Yalikun, N. Tanaka, Y. Shen, Y. Aishan, Y Nagahama, M. Oikawa, and Y. Tanaka, Anal. Sci., 2019, 35, 577.

6. H. Nakao and J.-D. Kim, Anal. Sci., 2019, 35, 1065.

7. E. Ayano and H. Kanazawa, J. Sep. Sci., 2006, 29, 738.

8. H. Kanazawa, J. Sep. Sci., 2007, 30, 1648.

9. H. Kanazawa, Chromatography, 2009, 30, 1.

10. E. Ayano and H. Kanazawa, Anal. Sci., 2014, 30, 167.

11. K. Nagase, M. Yamato, H. Kanazawa, and T. Okano, Biomaterials, 2018, 153, 27.

12. K. Nagase and H. Kanazawa, Anal. Chim. Acta, 2020, 41, 19.

13. Y. H. Bae, T. Okano, and S. W. Kim, J. Polym. Sci. Polym. Phys., 1990, 28, 923.

14. A. Suzuki and T. Tanaka, Nature, 1990, 346, 345.

15. T. Tanaka, Phys. Rev. Lett., 1980, 45, 1636.

16. Y. H. Kim, Y. H. Bae, and S. W. Kim, J. Controlled Release, 1994, 28, 143.

17. H. Kobayashi, M. Nishikawa, C. Sakamoto, T. Nishio, H. Kanazawa, and T. Okano, Anal. Sci., 2009, 25, 1043.

18. Y. Hiruta, M. Shimamura, M. Matsuura, Y. Maekawa, T. Funatsu, Y. Suzuki, E. Ayano, T. Okano, and H. Kanazawa, ACS Macro Lett., 2014, 3, 281.

19. Y. Hiruta, T. Funatsu, M. Matsuura, J. Wang, E. Ayano, and H. Kanazawa, Sens. Actuators, B, 2015, 207, 24.

20. A. Yamada, Y. Hiruta, J. Wang, E. Ayano, and H. Kanazawa, Biomacromolecules, 2015, 16, 2356.

21. Y. Hiruta, Y. Nagumo, Y. Suzuki, T. Funatsu, Y. Ishikawa, and H. Kanazawa, Colloids Surf., B, 2015, 132, 299.

22. Y. Hiruta, Y. Kanda, N. Katsuyama, and H. Kanazawa, RSC Adv., 2017, 7, 29540.

23. Y. Hiruta, R. Nemoto, and H. Kanazawa, Colloids Surf., B, 2017, 153, 2.

24. M. Matsuura, M. Ohshima, Y. Hiruta, T. Nishimura, K. Nagase, and H. Kanazawa, Int. J. Mol. Sci., 2018, 19, 1646. 
25. E. Ayano, M. Karaki, T. Ishihara, H. Kanazawa, and T. Okano, Colloids Surf., B, 2012, 99, 67.

26. J. Wang, E. Ayano, Y. Maitani, and H. Kanazawa, Int. J. Pharm., 2017, 523, 217.

27. J. Wang, E. Ayano, Y. Maitani, and H. Kanazawa, ACS OMEGA, 2017, 2, 316.

28. S. Yamanouchi, N. Katsuyama, Y. Hiruta, E. Ayano, and H. Kanazawa, Kobunshi Ronbunshu, 2018, 75, 116.

29. M. Maekawa-Matsuura, K. Fujieda, Y. Maekawa, T. Nishimura, K. Nagase, and H. Kanazawa, ACS OMEGA, 2019, 4, 6443.

30. R. Nemoto, K. Fujieda, Y. Hiruta, M. Hishida, E. Ayano, Y. Maitani, K. Nagase, and H. Kanazawa, Colloids Surf., B, 2019, 176, 309.

31. K. Nagase, M. Hasegawa, E. Ayano, Y. Maitani, and H. Kanazawa, Int. J. Mol. Sci., 2019, 20, 430.

32. M. Heskins, J. E. Guillet, and E. James, J. Macromol. Sci. Chem., 1968, A2, 1441.

33. S. Fujishige, Polym. J., 1987, 19, 297.

34. S. Fujishige, K. Kubota, and I. Ando, J. Phys. Chem., 1989, 93, 3311.

35. Y. Hiruta, M. Shimamura, M. Matsuura, Y. Maekawa, T. Funatsu, Y. Suzuki, E. Ayano, T. Okano, and H. Kanazawa, ACS Macro Lett., 2014, 3, 281.

36. Y. Hiruta, T. Funatsu, M. Matsuura, J. Wang, E. Ayano, and H. Kanazawa, Sens. Actuators, B, 2015, 207, 724.

37. T. Yakushiji, K. Sakai, A. Kikuchi, T. Aoyagi, Y. Sakurai, and T. Okano, Langmuir, 1998, 14, 4657.

38. H. Kanazawa, K. Yamamoto, Y. Matsushima, N. Takai, A. Kikuchi, and T. Okano, Anal. Chem., 1996, 68, 100.

39. H. Kanazawa, Y. Kashiwase, K. Yamamoto, Y. Matsushima, A. Kikuchi, Y. Sakurai, and T. Okano, Anal. Chem., 1997, $69,823$.

40. H. Kanazawa, T. Sunamoto, Y. Matsushima, A. Kikuchi, and T. Okano, Anal. Chem., 2000, 72, 5961.

41. H. Kanazawa, Y. Matsushima, and T. Okano, Trends Anal. Chem., 1998, 17, 435.

42. H. Kanazawa, T. Sunamoto, E. Ayano, Y. Matsushima, A. Kikuchi, and T. Okano, Anal. Sci., 2002, 18, 45.

43. M. Akimaru, K. Okubo, Y. Hiruta, and H. Kanazawa, Anal. Sci., 2015, 31, 881.

44. V. Bulmus, Z. Ding, C. J. Long, P. S. Stayton, and A. S. Hoffman, Bioconjugate Chem., 2000, 11, 78.

45. J. Kobayashi, A. Kikuchi, K Sakai, and T. Okano, J. Chromatogr. A, 2002, 958, 109.

46. H. Kanazawa, E. Ayano, C. Sakamoto, R. Yoda, A. Kikuchi, and T. Okano, J. Chromatogr. A, 2006, 1106, 152.

47. T. Nishio, R. Kanazashi, A. Nojima, H. Kanazawa, and T. Okano, J. Chromatogr. A, 2012, 1228, 148.

48. K. Sakata, K. Okubo, Y. Hiruta, E. Ayano, and H. Kanazawa, Kobunshi Ronbunshu, 2014, 71, 293.

49. Y. Hiruta, R. Kanazashi, E. Ayano, T. Okano, and H. Kanazawa, Analyst, 2016, 141, 910.

50. T. Mikuma, T. Kuroki, M. Yoshikawa, R. Uchida, Y. Hiruta, and H. Kanazawa, Chromatography, 2017, 38, 115.

51. Y. Maekawa, N. Okamoto, Y. Okada, K. Nagase, and H.
Kanazawa, Sci. Rep., 2020, 10, 8828.

52. A. J. Satti, P. Espeel, S. Martens, T. V. Hoeylandt, F. E. Du Prez, and F. Lynen, J. Chromatogr. A, 2015, 1426, 126.

53. K. Hosoya, F. Sawada, K. Kimata, T. Araki, N. Tanaka, and J. M. J. Fréchet, Macromolecules, 1994, 27, 3973.

54. K. Hosoya, K. Kimata, T. Araki, N. Tanaka, and J. M. J. Fréchet, Anal. Chem., 1995, 67, 1907.

55. H. Go, Y. Sudo, K. Hosoya, T. Ikegami, and N. Tanaka, Anal. Chem., 1998, 70, 4086.

56. U. M. Zanger and M. Schwab, Pharmacol. Ther, 2013, $138,103$.

57. D. W. Nebert and D. W. Russell, Lancet, 2002, 360, 1155.

58. K. S. Lee and S. K. Kim, J. Appl. Toxicol., 2013, 33, 100.

59. D. A. Volpe and P. V. Balimane, Bioanalysis, 2018, 10, 619.

60. V. C. Pillai, S. C. Strom, S. N. Caritis, and R. A Venkataramanan, J. Pharm. Biomed. Anal., 2013, 74, 126.

61. K. S. Oh, S. J. Park, D. D. Shinde, J. G. Shin, and D. H. Kim, J. Chromatogr. B, 2012, 895-896, 56.

62. Y. Maekawa, K. Yamazaki, M. Ihara, K. Nagase, and H. Kanazawa, Anal. Bioanal. Chem., 2020, 412, 5341.

63. B. Kelley, Biotechnology Progress, 2007, 23, 995.

64. H. Kanazawa, M. Nishikawa, A. Mizutani, C. Sakamoto, Y. Morita-Murase, Y. Nagata, A. Kikuchi, and T. Okano, J. Chromatogr. A, 2008, 1191, 157.

65. K. Okubo, K. Ikeda, A. Oaku, Y. Hiruta, K. Nagase, and H. Kanazawa, J. Chromatogr. A, 2018, 1568, 38.

66. K. Nagase, D. Inanaga, D. Ichikawa, A. Mizutani-Akimoto, Y. Hattori, and H. Kanazawa, Colloids Surf., B, 2019, 178, 253.

67. K. Nagase, A. Ota, T. Hirotani, S. Yamada, A. MizutaniAkimoto, and H. Kanazawa, Macromol. Rapid Commun., 2020, 41, 2070043.

68. M. Kanezawa, E. Ayano, H. Kanazawa, Y. Akiyama, and T. Okano, Chromatography, 2006, 27, 111.

69. E. Ayano, Y. Okada, C. Sakamoto, H. Kanazawa, A. Kikuchi, and T. Okano, J. Chromatogr. A, 2006, 1119, 51.

70. E. Ayano, Y. Suzuki, T. Nishio, Y. Nagata, H. Kanazawa, K. Nagase, and T. Okano, Chromatography, 2014, 35, 131.

71. Y. Hiruta, Y. Nagumo, A. Miki, T. Okano, and H. Kanazawa, RSC Adv., 2015, 5, 73217.

72. K. Nagase, N. Uchikawa, T. Hirotani, A. Mizutani-Akimoto, and H. Kanazawa, Colloids Surf., B, 2020, 185, 110565.

73. T. Nishio, R. Suzuki, Y. Tsukada, H. Kanazawa, T. Okano, and T. Miyabe-Nishiwaki, J. Chromatogr. A, 2009, 1216, 7427.

74. T. Mikuma, R. Uchida, M. Kajiya, Y. Hiruta, and H. Kanazawa, Anal. Bioanal. Chem., 2017, 409, 1059.

75. T. Nishio, E. Ayano, Y. Suzuki, H. Kanazawa, and T. Okano, J. Chromatogr. A, 2011, 1218, 2079.

76. E. Ayano, C. Sakamoto, H. Kanazawa, A. Kikuchi, and T. Okano, Anal. Sci., 2006, 22, 539.

77. E. Ayano, K. Nambu, C. Sakamoto, H. Kanazawa, A Kikuchi, and T. Okano, J. Chromatogr. A, 2006, 1119, 58.

78. K. Nagase, M. Watanabe, F. Zen, and H. Kanazawa, Anal. Chim. Acta, 2019, 1079, 220. 